\title{
Development of Application Based Footwork Training AIDS
}

\author{
Teguh Septianto Putra
}

\author{
Faculty of Sport, Universitas Negeri Medan, Medan, Indonesia \\ Email: teguh.nrn@gmail.com
}

\begin{abstract}
The purpose of this study is to produce a footwork training aid in badminton that follows the development of revolution 4.0 and adds variations and innovations in practicing badminton footwork. This research is a development research $(\mathrm{R} \& \mathrm{D})$ that follows the stages of development research, the process of the stages that the researcher takes to build a product up to the seventh stage of the Borg \& Gall development research. To find out whether the applicationbased footwork training aid media can run smoothly, small-scale trials and large-scale trials were carried out on a sample of 50 badminton athletes. Furthermore, from the small group trial of 20 badminton athletes, it showed the number was $86 \%$ with very feasible criteria, then from the large group trial of 30 athletes it showed a figure of $89 \%$ with the very feasible category. From the results of research and due diligence carried out by experts, namely badminton coaches, information technology (IT) experts, and sports experts, it shows that $95 \%$ is in the very feasible category. The results showed that the application-based footwork training aid media can operate perfectly and can add variety and innovation in practicing badminton footwork. So, the conclusion is that this application-based badminton footwork training aid meets the criteria of "Good" or "Feasible" so that it can be used to practice badminton footwork.
\end{abstract}

Keywords: Footwork, Application, Badminton.

\section{INTRODUCTION}

Sport has now become a trend or lifestyle for some people, even for some others, sports have become a basic need in their lives. Sport becomes very important because it cannot be separated from the basic needs of humans themselves, which in principle are always moving. The purpose of a person exercising is to increase the degree of dynamic health (healthy in motion), and static health (healthy at rest). In addition, exercising can improve and nourish the working system of the body's organs, increase the body's metabolism so that in the end a healthy body and soul will be obtained. In sports there are several factors that must be known and need special attention, namely physical, technical, tactical and mental factors.

To realize one's desire in achieving sports achievements is not easy and fast, sports achievements can be obtained after doing a series of systematic and repeated exercises with increasing number of training loads, time or intensity. Someone does exercise because it is a form of effort to achieve a goal. Exercise will also not be maximized without the role of a coach who organizes and provides repeated systematic exercises, training load, time and intensity. Exercises that are done properly usually take a lot of time. Hundreds of hours of hard work are needed by athletes to be able to gradually increase the intensity of their work, to repeat every form of exercise. Sports activities that have minimal elements of variation will make athletes feel bored in doing so, so that boredom in training will be detrimental to the progress of their achievements. To overcome this monotonous exercise, it would be better for the coach to find ways to make the exercises varied and look new, for example, training by utilizing the development of science and technology. Exercises like this will definitely match the current developments, so athletes will also be excited to practice with exercises that take advantage of science and technology developments.

The development of science and technology is also very necessary in the world of sports, for example the development of science and technology has been widely used in the field of sports, such as the use of goal line technology in football, eagle line in tennis and badminton, and many other technological developments 
that have been used in sports. sports world. In addition, the development of science and technology can also be used in training sessions, of course the development of science and technology in the training session can simplify and make the meaning of the exercise maximized, also the development of science and technology in this training session can add variations to the exercise so that athletes do not get bored with monotonous training. So that the development of science and technology in this training session must also be considered by the coach.

Exercise is a systematic sport activity over a long period of time, progressively and individually improved and leads to the characteristics of human physiological and psychological functions to achieve the goals that

have been set (Bompa, 1999:78). The main purpose of training in sports is to help athletes improve their sports skills and achievements as much as possible (Harsono, 1992: 1).

One type of exercise that is monotonous and has not been touched by the development of science and technology, one of which is footwork exercises, this conclusion can be obtained directly through surveys at clubs and interviews with the trainers concerned. The survey at this club was carried out by distributing a needs analysis questionnaire to athletes, the questionnaire consisted of 7 (seven) questions about footwork exercises and what footwork training aids the athletes used.

Exercise to master the footwork is guided by habituation, because the quality of good footwork is determined by the rhythm and accuracy of the steps. So to be able to master the expected quality is to practice as often as possible by simulating movements that are in accordance with what happens in the match (Sapta Kunta Purnama, 2010:27). To master quality footwork, coaches must provide athletes with a systematic and planned training program, because good and rhythmic footwork must be done repeatedly and routinely. Footwork exercises must be carried out continuously to maintain the level of speed and accuracy of footwork. The training provided by the coach must also be varied and innovative so that athletes do not get bored quickly with the same exercises every day.

Zulfan Heri, (2019:2) in the journal of sports science volume 18 (1). The development of training aids is needed by the coach in order to train the athlete's abilities and be included in the training program. Researchers tried to make media for footwork training tools using application software. With the development of this new tool, it can be optimized so that footwork training becomes attractive to athletes and is a breakthrough for coaches to add training innovations in footwork.

\subsection{Exercise}

According to Bompa (1994) in Awan Hariono (2006:1) exercise is a person's efforts to improve the organism and its functions to optimize sports performance and performance. In order for the training to achieve optimal performance results, the program/form of training that is prepared should consider the basic abilities of the individual, taking into account and following the principles or principles of training. Nurkadri (2017:2) Journal of Achievement, Volume 1, Issue 2. Coaching work should not be used just for fun. A coach must not, in addition to having a coach's academic background, experience, must also be able to apply sports coaching sciences such as exercise physiology, sports psychology, sports biomechanics, and also other supporting sciences that can help in achieving success in doing sports. his role as a coach.

\subsection{Badminton Footwork}

Footwork exercises get used to the feet to reach all points of the field with regular and correct steps so as to minimize the possibility of "step dead" or irregular steps that can result in dead steps and even injury. The function of the feet in the badminton game is to bring the body to a certain point in accordance with the arrival of the shuttlecock, then the player must make a movement to hit the shuttlecock precisely and carefully in a certain direction on the opponent's court.

Sapta Kunta Purnama (2010:26) argues that the basic principle of footwork in badminton is that the foot that matches the hand used to hold the racket when hitting always ends in the direction of the hand. Footwork consists of several movements that must be carried out into a harmonious series of movements.

\subsection{Application}

An application is a sub-class of computer software that utilizes the capabilities of a direct computer to perform a task the user wants. Understanding Applications according to Barry Pratama (2015:6): 
- An application is a unit of software created to serve the needs of several activities.

- An application is a complete system that performs a specific task.

- Database application consists of a set of menus, forms, reports and programs that meet the functional needs of a business unit / organization / agency.

The design of this application-based footwork training tool was developed because it started from an initial concept that was developed systematically and according to need, so that the development of application-based training aids is expected to have effectiveness, efficiency, and follow the development of the industrial revolution 4.0 which is feasible to use. Before the footwork application is completed and ready to be used or tested, the researcher designs the basic prototype form of the application-based footwork training tool itself, after the design has been determined, the next step is the researcher collects what is needed to be able to produce a device product. software for footwork training tools based on this application, namely Microsoft Visual Studio, laptop/notebook, speakers, remote (keyboard number).

The functions of the buttons on the remote for the app-based footwork training aid are as follows:

1. Button $1=$ rear left

2. Button $2=$ back

3. Button $3=$ rear right

4. Button $4=$ left

5. Button $5=$ middle

6. Button $6=$ right

7. Button $7=$ front left

8. Button $8=$ front

9. Button $9=$ front right

10. Num Lock $=$ lock or activate the remote

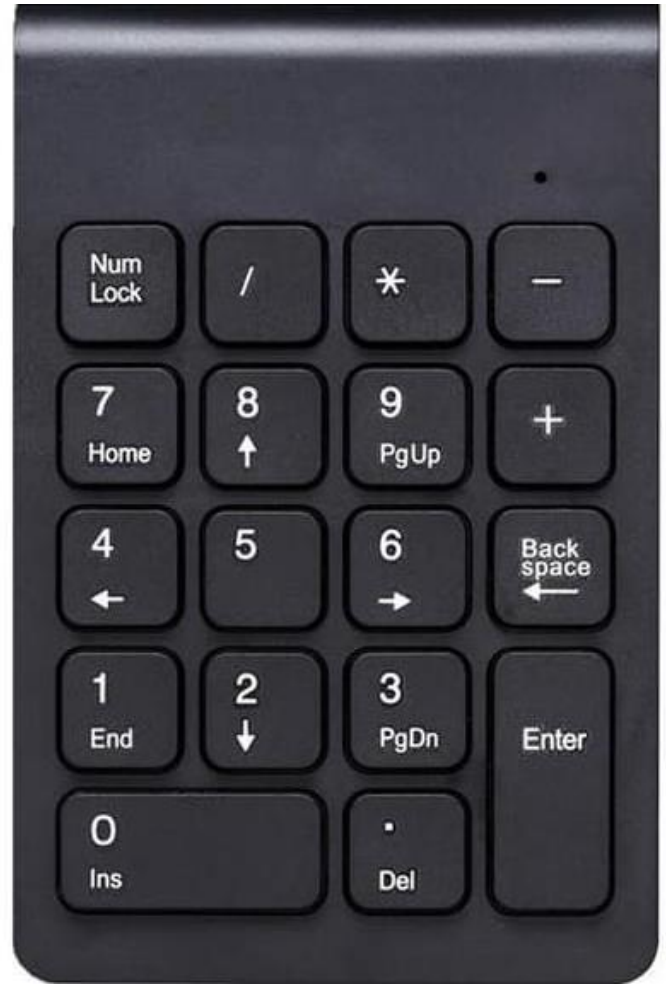

Figure 1. Remote

When entering the main menu view of the footwork exercise application, it is found on the "Footwork App" menu, then the first step to enter the footwork exercise application program is to click the "Footwork App" menu. A login field will appear, enter the user name and password.

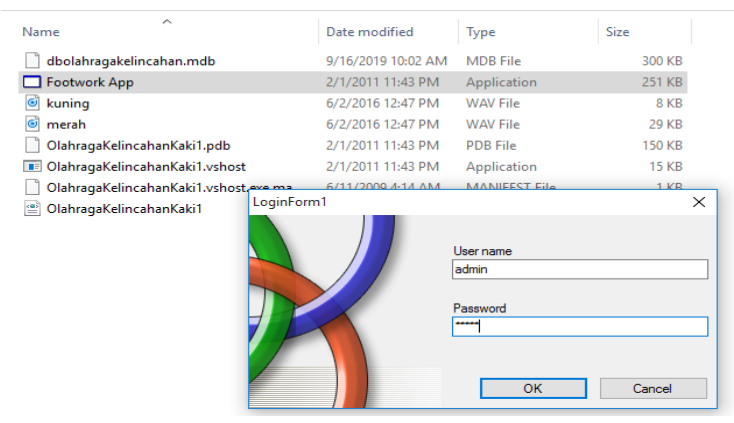

Figure 2. Menu Display

The display of this application-based footwork training tool is on the parent data menu, if we click on the parent data menu, there will be a choice of displaying the footwork exercise application with time or without time which has the intention of how long it takes a red light to turn on and back off to green. As explained earlier, the "time" selection pattern is how long the red light turns on and turns green when the 
time has run out, how long the red light is on is expressed in seconds or seconds and can be set in the settings option menu in the footwork app display. The "no time" menu here means that the red light will go out immediately after we release the remote button, if we keep pressing the remote, the red light will stay on.

Below is a screenshot of the footwork exercise application display when one of the buttons on the remote is pressed by the trainer. If the button 1 on the remote is pressed, the red light will light up, this light is an instruction or signal given by the coach to the athlete to do footwork towards the light. This light will return to green if the time we want or we input in the settings has run out. The green light will come back on if the coach presses the button on the remote again.

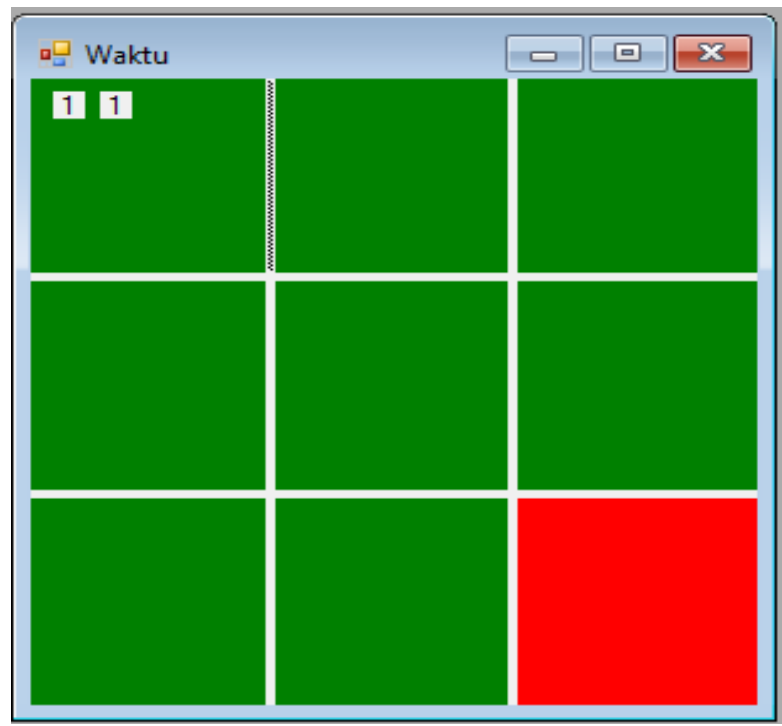

Figure 3. The red light is on when the remote button is pressed

\section{METHOD}

The research procedure carried out by the researcher in this development was adapted from the development steps developed by Borg \& Gall with limitations. However, from these development steps, the researcher limits it to the seventh stage, as for the development steps, which include:

- Research and Information Collecting

- Planning

- Develop Preliminary of Product

- Preliminary Field Testing

- Main Product Revision

- Main Field Test

\section{- Operational Product Revision}

The research on the development of applicationbased footwork training aids in the badminton sport was carried out starting from observations at badminton clubs to look for problems carried out in August 2019 to a thesis result seminar to be held in May 2021. The techniques used for data collection in the study This is a questionnaire or questionnaire, interviews, documentation, and observations.

In this study, data analysis techniques were used with quantitative descriptive analysis techniques with percentages. This technique is used to obtain quantitative data analysis obtained from the distribution of questionnaires. With a Likert scale, the variables to be measured are translated into variable indicators. Then the indicator is used as a starting point for the preparation of instrument items which can be in the form of statements or questions. The collected data were analyzed using quantitative descriptive analysis techniques which were expressed in the distribution of scores and percentages of the predetermined rating scale categories. After presenting in percentage form, the next step is to describe and draw conclusions about each indicator.

Table 1. Eligibility category according to Arikunto

\begin{tabular}{|l|l|}
\hline Percentage of Achievement & Interpretation \\
\hline$<21 \%$ & Totally Disagree \\
\hline $21 \%-40 \%$ & Disagree \\
\hline $41 \%-60 \%$ & Medium \\
\hline $61 \%-80 \%$ & Agree \\
\hline $81 \%-100 \%$ & Totally Agree \\
\hline
\end{tabular}

Source : Arikunto (2009:44)

\section{RESULT}

From the needs analysis conducted by researchers on 15 badminton athletes, the results of the questionnaire distributed to 15 athletes during the needs analysis activity concluded that they really needed footwork training aids with a percentage of $100 \%$. This phase I product trial will be carried out by 20 athletes from the PB badminton club. Adisya as a sample trial that will be carried out at the Rantau Prapat sports building, this phase I product trial aims to obtain assessments and input from badminton coaches, IT media experts, and sports experts on the development of footwork training tools based on sports applications. badminton. The 
Phase II Product Test was carried out by 30 athletes from the PB badminton club. Adisya as a trial sample that will be carried out at the Rantau Prapat sports building aims to provide an assessment and input on the development of application-based footwork training aids in badminton so that it meets the criteria for theoretically feasible and empirically feasible.

From the table of the results of the recapitulation of the assessment of the badminton coach stage II in the attachment sheet it is known that the total score of the respondents $(\mathrm{X})$ is 82 , the total score $(\mathrm{Xi})$ is 85 so that the percentage is $96 \%$ of the specified criteria and it can be said that the development of application-based footwork training aids in the badminton sport meets the Very Eligible criteria $(81 \%-100 \%)$ so that it can be used.

From the table of results of the recapitulation of the assessment of IT media experts stage II on the attachment sheet it is known that the total score of respondents $(\mathrm{X})$ is 77 , the total score $(\mathrm{Xi})$ is 80 so that the percentage is $95 \%$ of the specified criteria and it can be said that the development of footwork training aids application-based in the badminton sport meets the Very Eligible criteria $(81 \%-100 \%)$ so that it can be used.

From the table of results of the recapitulation of the assessment of sports experts stage II in the attachment sheet it is known that the total score of respondents (X) is 83 , the total score ( $\mathrm{Xi}$ ) is 85 so that the percentage is 95\% of the specified criteria and it can be said that the development of footwork training aids is based on applications in badminton meet the Very Eligible criteria $(81 \%-100 \%)$ so that they can be used.

Of the 30 large group trial athletes with a total score of 2020 divided by a maximum score of $2250 \times 100 \%$ resulting in a presentation of $89 \%$ with Very Eligible criteria.

\section{CONCLUSIONS AND SUGGESTIONS}

From the results of the research that has been done, the researcher concludes that this application-based badminton footwork training tool is feasible to be used in the implementation of badminton footwork training activities. With the development of application-based badminton footwork training aids that the researchers developed, the trainer has many choices of training aids so that the training program becomes interesting and can make athletes not bored with footwork exercises that are always the same and without variations.

This application-based footwork training tool is expected to provide convenience in the implementation of badminton footwork exercises and make athletes able to master footwork movements that are shrewd, rhythmic, and can reach all corners of the field quickly. This training aid is also expected to increase the motivation of athletes and make athletes enthusiastic in practicing footwork.

This study has the implication that this applicationbased badminton footwork training tool can increase enthusiasm due to curiosity and can increase a sense of motivation in athletes so that later athletes can master footwork techniques and movements well and rhythmically. This application-based footwork training tool has also modernized the previous footwork training tool, this exercise tool has followed the development of the current industrial revolution 4.0.

This application-based badminton footwork training tool product can be input and consideration for badminton coaches to train or students who are researching badminton footwork skill techniques or researching footwork training aids themselves.

For the process of distributing this application-based badminton footwork training aid product to a wider target, the researcher suggests that this training aid must pass all stages of development from Borg and Gall before being disseminated so that this footwork training tool is perfect and can be used in all badminton clubs.

\section{REFERENCES}

[1] Arikunto, Suharsimi. (1991). Prosudur suatu penelitian pendekatan praktis. PT Bina Angkasa: Jakarta.

[2] Harsono. (2000). Gerakan Nasional Garuda Emas Panduan Kepelatihan. Jakarta : oktober 2000.

[3] Nurkadri (2017), Perencanaan Latihan. Jurnal Prestasi, Volume 1, Issue 2. 